\title{
Inmunidad de María de la culpa original
}

Antes de adentrarnos en la exposición de la doctrina inmaculista de Tomás de Strasbourg, conviene, para apreciar mejor el mérito de la misma, echar una mirada al ambiente histórico doctrinal de su tiempo y, preferentemente, de la Orden Agustiniana. Porque es en este punto donde la persona del Argentinense adquiere mayor relieve y reviste características propias.

Ambiente historico Doctrinal.

Ambiente general.-Fijando nuestra mirada en las posturas que adoptaron los grandes doctores escolásticos de los siglos xiI, xIII y xIv frente al problema de la Concepción Inmaculada de María, podemos distinguir dos tendencias bien diferentes: de negación y de afirmación del privilegio ${ }^{1}$. En este período -época de iniciación de investigaciones científicas - se comparan unos dogmas con otros, se indican sus enlaces y sus armonías. Le toca el turno a la Inmaculada, y el privilegio blanco de María es colocado sobre el tapete de la discusión ${ }^{2}$.

Mientras en las aulas se acumulan sombras, en los templos, en las

1 No es nuestra intención hacer una historia detallada de la controversia -cosa que el lector puede fácilmente ver en los Manuales de Teología Dogmática- sino una ambientación somera. Una exposición amplia de la cuestión puede verse, v. gr., en B. PLAZzA, Causa Immaculatae Concientionis sanctissimae Matris Dei Marriae Dominae nostrae, actio 7, Coloniae 1751, 308-345; X. LE BACHELET, "Immaculée Conception": D. T. C., VII/1, París 1927, 979-1.108; Fr. GuImerces, "La doctrine des theologiens sur l'Immaculée Conception de 1250 a 1350": Etudes franciscaines 3 (1952) 181-203; 4 (1953) 23-53, 167-187; H. AMERI "Doctrina theologorum de Immaculata B. V. Mariae Conceptione tempore Concilii Basiliensis": Bibliotheca Immaciulatiae Conceptionis 4, Roma 1954, 60-243; C. BALIC, Johannes Duns Scoto et historia Immaculatale Concerotionis, Roma 1955; J. A. AlDAMA, Sacrae Theologiae Summa. Mariologia, III, B.AC, Madrid 1956, 351-355; G. M. RoschiNI, La Madre de Dios según la fe y t" teología. Versión española de Eduardo Espert, II, Madrid 1958, 43-60.

2 Cfr. J. DuHR, "L'evolution du dogme de l'Immaculée Conception": Nouvelle revue theologique 73 (1951) 1.013-1.032; J. M. de GoICOCHEA, "Proceso historial del dogma de la Inmaculadia Concepción": Verdad y vida 5 (1947) 149-169. 
piazas, en las calles, en el campo, el pueblo permanece en su fe, ajeno a las sutilezas de escuela, y. cada año enciende nuevas luces al celebrar la fiesta en honor de la Inmaculada Concepción de María ${ }^{3}$.

Los adversarios del privilegio concepcionista prevalecen, al menos en cuanto al número ${ }^{4}$, pero, por fin, brota del seno de la discusión la luz. La victoria de los asertores del privilegio mariano ${ }^{5}$ conquista para sí a los nuevos y últimos representantes de la Escolástica - siglo xiv principalmente- que no se dejan alucinar por las aparentes contradicciones dogmáticas: universalidad del pecado y de la redención y preservación de María de todo pecado y, en especial, del pecado original. La victoria es aplastante en el terreno de la discusión y los teólogos, uno tras otro, ruelven sus armas en defensa de lo que el pueblo había profesado.

- En la Orden Agustiniana.-En lo que se refiere a la doctrina inmaculista, la Escuela Agustiniana hubo de pasar por las mismas vicisitudes que otra cualquier escuela de este período. En ella podemos distinguir dos períodos: uno de oposición y otro favorable a la tesis inmaculista ${ }^{6}$.

3 Cfr. A. Noyon, "Leis origines de la fête de l'Immaculée Conception en Occident": Etudies 100 (1904) 763-789; E. VACANDARD, "Les origines de la fête et du dogme de l'Immaculée Conception": Revue clerg. franc. 62 (1910) 38-41.

4 Entre los que admitieron la existencia del pecado original en María suele enumerarsse a San Bernardo, Alejandro de Hales, San Buenaventura, Juan de la Rochelle, San Alberto Magno, Santo Tomás, Egidio Romano, Pedro de Tarantasia, Enrique de Gante, Aufredo Gontier, Gregorio de Rímini, Alvaro Pelayo, Aguistín de Ancona, Juan de Poilly, Juan de Nápoles, etc. Cfr. V. de Bandeluus de Castronovo, Disputiatio sollemnis de Concieptione B. Vixginis, 1502 (sin luglar die impresión); P. Alva y AstoraA, Sol veritatis crum ventilabro seraphico pro candida ajurora Maria in suo Comceptionis ortu samcia, puma, immaculatia et a peccato originali proeservata, Matriti 1660; X. LE BACHELET, o. c.; J. A. ALDAMA, o. c.; B. Plazza, o. c.; H. AMERI, o. c.

5 Diefensores del privilegio inmaculista fueron, entre otros, Eadmero, Nicolás de S. Alibant, Pedro Pascasio, Kaimundo Lulio, Guillermo de Ware, Juan Duns-Scoto, Franciscio de Mayron, Pedro Aureolo, Tomás de Strassbourg, Juan Baconthorp, Herman de Schildizs, Juan Taulero, eitc. Entre las Univerisidades que se unieron, si bien algo más tarde, en la defensa del privilegio tenemos la de París 1497, Colonia 1499, Viena, Valencia, Barcelona, Salamanca 1618, Coimbra, etc. Cifr. P. AlBA y Astorla, Militia Immaculatae Compentionis Virginis Mariale cantra malitiam originalis infectionis meccati, Lovanii 1663; igualmente pueden congultarse las obras inidicaidas en la nota 1.

6 Ponemosi especial atención en la doctrina inmaculista dentro de la Orden Aguistiniana por tocarnos más de cerca y por la importancia que en ella ha temido y tienei. Tomás de Strasibourg or de Argentinai Para un conocimiento más amplio y perfiecto de la cuestión, remitimos a los siguientes estudios: E. D. CARRETERo, "Tradición Inmaculista Aguistiniana a través de Egidio de la Presentación": La Ciudad de "Dios 166 (1954) 342-386; A. BLANC0, "Lai Inmaculada Concepición y la Eiscuela Aguistiniana": España y América 6 (1904) 446-477, 513-520; G. Tumminerlo, L'Immadalata Conceziome di Mamia e la Scuola Agosti- 
Egidio Romano, el fundador y Maestro de la Escuela Agustiniana, fue el primero en plantearse el problema. Su solución está en armonía con los dogmas de la universalidad del pecado original y de la redención, uniéndose al común sentir de sus maestros y contemporáneos: la Virgen María fue primero concebida en pecado original y luego santificada. Pero entre la concepción en pecado y la santificación, el tiempo transcurrido fue muy breve, casi imperceptible?

Las razones del Maestro Egidio -en realidad eran las comunes de su tiempo - tuvieron buena acogida entre los escolásticos agustinos medievales, aún después de iniciado y prevaleciendo ya el período de reacción o favorable a la Inmaculada. Como seguidores de la sentencia de Egidio podemos enumerar al Bto. Santiago de Viterbo ${ }^{8}$, Agustín de Ancona ${ }^{9}$, Enrique de Friemar ${ }^{10}$, Gregorio de Rímini ${ }^{11}$, Hugolino Ma-

niana del secolo XIV, Roma 1942; A. SAGE, "La doctrine et le culte de Marie dans la famille augustinienne", en Marria (Diu Manoir), II, París 1952, 694 sis.

7 EgIDIo Romano, $\$ 1316$, trata la cuestión en muchas de sus obrais: Quodlibeta, Expositiol in Salutationem Anglililcam, Commentarium in IV Libros Sententiarum. He aquí algunas de sus afirmaciones:

"Beata ergo Virgo, quia concepita fuit secundum amplexum maritalem, sicut coeteri homines, fuit in peccatio originali concepta, ...Dicemus enim, quod beata Virgo fuerit in originali peccato: concepta, et pier aliquam morulam, sive pelr aliquod tempus, lidet valde brevem, stieterit in huiusmodi oriainail" (Quodl. VI, q. 20).

"Etiam in hac Virgine benedicta, quia ab omnibus actualibus pecicatis fuit libera, et $a b$ originali in quo conclepta fuerat, fuit in nativitate sancificata..." (Expositio in Salutationem Angelicam, Ave, Roma 1555, fol. 8 A).

"Ald quaestionem engo propositam, quantum spectat ad Virginen Beatam, dicemus quod fuit donceipta in originaili, sicut et aliae muliemes, sed pie creadendum est, quod quasi statim, postquam fuit in originali concerpta, fuit ab originali mundatia et in utero sanctificwa... Tripliciter engo poterimus Virginem fuisise conceptam in origtinali peccato..." (In 3 Sient., d. 3, q. 1, a. 1 resolutio). Cfr. además, In 3 Sent., d. 3, q. 1, a. 1-4 passim; In 2 Sent., d. 30, q. 1, a. 3, resolutio; Ibŕd., d. 29, q. 1, a. 2, dubitatio 4 lateralis; Ibŕd., d. 32, q. 1, a. 2, aid 5. Cfr. G. Tumminello, o. c., VI-VII; E. D. Carretero, a. c. 345-349.

8 P. de Alva y AsTorga, Rladii solis zeli seraphici coeli veritatis pro Immaculatae Concieptionis mystierio Virginis Mariale..., Lovanii 1666, 1570-1573. recoge varios textos del maesitro agulstino. Santiago de' Viterbo relativos al tema de la Concepción de María.

9 Agustín DE ANCONA, †1328, expone su parecer en In Scilutationem et Annuntiatianem amgeläclam ad Diengaram Viraniem ex Evanaelio $S$ Lucae, c. 1; Tralcatatus in orationem Domitniclam; Expositho in ommes Epistolas D. Pauli; Sermones die Sanctis ad Clerum. Así, v. gr., escribe: "Dicamus engo, quod beata Virgo si non fuisset in pecclato orignhali concienta, tria inconvenientia seruerentur..." (In Salutationem et Annuntiationem angelicam..., lectio 2, Roma 1590, 16).

10 Se encuentran varios passajes de este agustino sobre el tema de la Concepción de María en la obra anteriormente citada del P. de ALVA Y Astorga.

11 Aisí se expresa: GReGorio DE RímINI, $\dagger 1358$, sobre el privilegio concepicionista: "De primo quaidem non quaeritur an fuerit rossibile eam comeipi sine tali pecciato. Sed an de facto fuerit sine ullo concepta: cum de hoc per humanam rationem certitudo haberi non possit, in hac parte id potius tienendum mihi videtur quod magis consonum esst Slacrae Scripturae et dictis sanctorum; et 
labranca de Orvieto, Jordán de Sajonia o de Quedlimburg ${ }^{12}$, Alfonso Vargas de Toledo, Bonifacio de Asti, etc. ${ }^{13}$.

Aunque vinculado a Egidio Romano no sólo por razón del hábito, sino también en los principios doctrinales esenciales de la Escuela, Tomás de Strasbourg se apartó, sin embargo, de él en la solución del privilegio de inmunidad de pecado en María. Negando en María todo pecado, tanto original como personal, abrió en la Orden Agustiniana la corriente inmaculista y poco a poco su piadosa sentencia se impuso en toda la Orden.

Al lado de Tomás de Argentina, un ejército compacto de agustinos ilustres, especialmente en Alemania, salió valerosamente en defensa del privilegio concepcionista, componiendo tratados sobre el tema y ensalzando a la Purísima desde el púlpito y desde las cátedras de Teología. Son dignos de mención Hermann de Schildizs ${ }^{14}$, Pablo Véneto, Juan Hiltalinger de Basilea ${ }^{15}$, Jaime Pérez de Valencia ${ }^{16}$, Agustín Favaroni

iideo, absique braeiudicio melioris sententiae, et salva semper reverentia matris Dei, diclendum mihi videtur eam fuissie cum originali pegcato aonclentam" (In 2 Sent., d. 30-33, q. 2, a. 1).

12 JORDÁN DE SAJONIA o de QUEDLIMBURG, $\$ 1380$, expuso la doctrina contra el privilegio die la Inmaculada en su obra Opus postillarum et Sermones de Evangelizis dominicialibus sielu de tempore, elscrita en 1358 y publicada en Argentina (Strasbourg) en 1483 .

En la Biblioteca idel Colegio de PP. Agrustinos de Valladolid se encuentra un manuscrito die esta obra - contiene isolamente los Sermones die Adviento y Cularesma-, coppiado en 1431. Esitá esscrito en folio sin numerar y a doble columna. Figura en la colección de la Biblioteca con el múm. 44.102.

13 Nos limitamos a reproducir lass citas y anotiaciones der aquellos autores que hemos podido consultar directamente. Para los restantes remitimos a los estudios particulares dedicados al tema, v. g'x., E. D. CARRETERo, a. c., 349-350; G. TUMMINELLo, o. c., VII-VIII.

14 HermanN DE SCHILDIZs, $\$ 1357$, expone ampliamente la sentencia favom rable al privilegio inmaculista en su obra Tractatus die Comcentione gloriosaie Virginis. Esitá publicado por P. DE ALVA y AsTORGa en isu obra Monumenta antiqua Immaculatae Comckptilonis ex varin's authoribus antiquis..., I, Lovanni 1664, 139-182.

Un estudio bastante amplio de stu doctrina puede verse en G. TUMmINELLo, o. c., 29-50; E. D. CARRETERo, a. c., 354-361.

15 JUAN HILTALINGER DE BASIlea, $\dagger 1392$, afirma la doctrina inmaculista en sus Responsiones y en su Quedlibeto, hor diesconocido. Cfr. G. TUMmineluo, o. c., $51-60$.

16 JAIME PÉREZ DE VALENCIA, $\$ 1492$, Obispo Cristopolitano y auxiliar de Valencia, escribió runa exposición muy completa en torno a la Inmaculada en su obra Expositio in centum quihquaginta Psalmos... et in Canticum Virginis Mariaue.

Trata el privilegio inmaculista en la exposición al Salmo 45 y principalmente en el comentario al Magnificat del que tomamos" esitas líneas: "... ergo pier gratiam sanctificiantiem in sua creatione fuit oraeservata ab omini pecato. Et per cionsequenis peccatum naturale non transivit in eius animam quoad culpam nec in eius compuis quoaid morbum concupiscentiae actualiter post animationem... eo quod singulari gratia et privilegio fuit ante legem datam. (O. c., Luglduni, 1518, 423 v.). Cfr. E. D. CARRETERo, a. c., 366-372. 
de Roma, Antonio de Rampelogis ${ }^{17}$, Buenaventura de Padua, etc. ${ }^{18}$. Así, en la historia de la Escuela Agustiniana, Tomás de Argentina o de Strasbourg se apunta una gloria aparte por su visión anticipada y certera en la armonización de los dogmas católicos que juegan el principal papel en el misterio de la Inmaculada Concepción de María, si bien es clara y manifiesta, como veremos, la influencia que las ideas sentenciarias, anselmianas y franciscanas ejercen en su exposición teológica del misterio.

Doctrina inmaculista de Tomás de Argentina.

Cuestiones introductorias.-Cuatro elementos integran o componen el complejo concepto de "Inmaculada". Elementos que el Argentinense no pierde de vista al estudiar el singular privilegio de María en su concepción. Son los siguientes :

1. La creación del hombre por parte de Dios en estado de justicia original.-Sobre la justicia original Tomás de Strasbourg, siguiendo al "Doctor Fundatissimus" y Maestro de la Escuela Agustiniana, Egidio Romano ${ }^{19}$, tiene una concepción especial: esencialmente consiste en una gracia "gratis data", don especial y sobrenatural.

Esta gracia "gratis data", este don especial y sobrenatural conferido por Dios al hombre, no comprende las gracias "gratis datas" que se refieren a las perfecciones naturales, otorgadas al hombre sin mérito alguno. Incluye más bien una naturaleza perfectísima. En virtud de esa gracia "gratis data" y sobrenatural, el hombre puede obtener la inmunidad de la concupiscencia, la inmortalidad y la fuerza para evitar el pecado.

17 ANTONIO DE RAMPELOGIS escribió en 1390 su obra Figurae Biblicae praeclarissimi viri. Al tratar de la Virgen María escribe: “... adeo replevit ipsam sanctitatis gratia, ut tam ab ariginali quam ab detuali pecdato dieinesems esset munda..." (O. c., Lugiduni 1525, 50, XXIII r.).

18 Estudioś más ampliosi y lista más completa de los agustinos defensores de la doctrina inmaculistia, cfr. E. D. CARRETERo, a. c., 350-386; G. TUMMINELLo, o. c., 60-62; A. SAGE, 1. c.; A. BLANCO, l. c.

19 La doctrina egidiana sobre la justicia original ha sido ampliamente estudiada por Agostino V. LA CALLE, O. S. A., en su trabajo La justizig di Adamo e il pecciato originale secondo Egridio Romano, Palermo 1939. En las piáiginas 59-61. estudia el influjo de Egidio en Tomás de Strasbourg. Cifr. adiemás G. DÍAz, De peccati originatis essentia in Schola Augustiniana proetridentina, El Escorial 1961, 52-68; A. ALFARo, Lo nathural y lo sobrenatural. Estudio histórico des de Santo: Tomás hasta Cayetano, 1274-1534, Madrid 1952, 374-380. 


\begin{abstract}
"Quantum ad tertium articulum dico primo, quod homo antequam peccivit, habuit gratiam gratis datam, non solum quantum ad naturales perfectiones quae sibi a Deo perfectissime fuerunt collatae sine suis meritis, et per consequensi totaliter gratis; sed etiam habuit gratiam gratis datam quantum ad donum gratuitum supernaturale, scillicet, originalem iustitiam, qua potuit immortaliter vivere semper, et immaculatus corporaliter, et spiritualiter perpetuo permanere" 20 .
\end{abstract}

La gracia "gratum faciens" o gracia santificante queda, al contrario, excluída por el Argentinense del estado de justicia original.

"Secundo dico, quod primus homo antequam peccavit non habuit gratiam gratum facientem" 21 .

"Deus hominem non creavit cum graitia gratum faciente" 22.

El don de la justicia original concedía a Adán la facultad de evitar el pecado, el no ser enemigo de Dios. Pero no el poder hacer actos meritorios y alcanzar así la gloria, que sólo puede conseguirse mediante la gracia santificante o "gratum faciens" ${ }^{23}$. Tomás de Strasbourg funda su afirmación primeramente en la autoridad del Maestro de las Sentencias ${ }^{24}$ y de Hugo de San Víctor ${ }^{25}$. En el estado de justicia original el hombre podía permanecer en el estado de felicidad y rectitud en que fue creado, pero no podía adelantar en el bien ni merecer la visión beatífica. Necesitaba un don divino, la gracia "gratum faciens" ${ }^{26}$.

En segundo lugar, recurre al testimonio de San Agustín ${ }^{27}$, para

20 In 2 Sent., d. 28-29, q. 1, a. 3, concl. 1. Sobre la doctrina de la justicia original según nuestro autor cfr.: G. TUMMINELLo, L'Immacolata Concieziomo di Maria e la Scuola Agostiniama diel seciolo XIV, Roma 1942, 2-5; G. DíAz, o. $c . ;$ A. Alffaro, o. c., 384 sis.

21 Ibid., concl. 2.

22 In 2 Sent., d. 4-5, a. 1, a. 2, concl. 2. Nuestro autor con esta afirmación arguye a pari que tampoco los ángeleisı fueron creados en gracia santificante.

${ }_{23}$ "Ad hoc, quod actus cuiuscumque cmeaturase sit meritiorius, necessario requiritur gratia gratum flaciens: quia actus naturam excedens necessario innititur alicui supernaturali principio, quo natura supernaturaliter adiuvetur; seid omnis actus meritorius vitae aeternae de condigno excedit naturam creatam...".

“Talis visio - divinae essentiae-, cum sit omnino supernaturalis, non potest ab aliquo adipisci nisi mediante gratia Dei..." (In 2 Sent., d. 32-33, q. i, a. 3 , concl.).

24 Liber II Sententiarum, d. 24 , c. 1.

25 De Sacramentis clhristiana fidiei, 1. I, pans: 6: PL. 176, 263-288.

26 "Si habuissent talem gratiam, tunc poituissent proficere, et non solum stare. Consequens est falsum, ut patet, per Magistrum in littera, et per Hugonem libro pximo de sacramentis parte 6; ergo, etc." (Thomas DE ARGenTINA, " In 2 Sent., d. 28-29, q. 1, a. 3, concl. 2).

27 S. Augustinus, De Civ, Dei, 1, 11, c, 12: ML. 41, 328. 
quien el estado de la presente economía sobrenatural es superior a aquél en que fue creado Adán ${ }^{28}$.

Como don gratuito y sobrenatural, la justicia original no era debida a la naturaleza humana estricta y absolutamente. Sin embargo, en opinión de Tomás de Argentina, existía una cierta exigencia a otorgar al hombre la justicia original. Mejor que exigencia, se daba por parte de Dios cierta conveniencia o decencia de crear al hombre en este estado de justicia, habida cuenta de su fragilidad.

"Et istud decuit divinam bonitatem; quia alias homo prius sustinuisset poenam, quam commisisset culpam" 29

Sin la justicia original la naturaleza humana sería un tanto imperfecta. Sin este don gratuito y sobrenatural, el hombre estaría destinado a morir, sería incapaz de someter las fuerzas de las potencias inferiores a la razón y, por tanto, inclinado a desobedecer a Dios y caer en el pecado $^{30}$. De ahí la congruencia por parte de Dios en crear al hombre en justicia original. Una vez más quedarían patentes sus atributos divinos, según se manifiestan en la naturaleza.

Este don gratuito y sobrenatural, por su naturaleza y oficio, es denominado con toda propiedad justicia, pues se ordenaba a la perfecta rectitud del alma y sus potencias.

28 "Praeterea, si habuisisent talem gratiam: tunc iustus homo pro statu praesentis vitae quantum ad spem futurae gloriae non haberet aliquam praerrogativam sumer statum ipisiusis Adiae ante peccatum. Consequentia patet, quia si homo primus habuisiset gratiam, tunc non minus bene mereri potuisset futuram oloriam; auam iustuis istius status. Sed falsitas consequentis patiet per Augustinum 2 lib. De civ. Dei, ubi ait quod primus homo in paradiso quamtum ad delectationem praesentis boni beatior emait, quam quicumque iustuis in hac infirmitate mortali; quantum autem ad spem futuri boni beatior esit quilibet iustus in quibuslibet corporis cruciatibus, auia certa spe potest sine fine et sine molestia societatem angelorum habere". (Thomas DE ARGENTINA, Ibíd.). Cfr. además, In 2 Sent. di. 4-5 a. 1, a. 2, concl. 2, 3 .

29) Ibid., d. 28-29, q. 1, a. 3, concl. 1.

30 "Praeterea, non decuisset Deum incorporalem et intellectualem animan a principio transferre in corpus, quod necessitatem habuisset moriendi: sed sine originali iustitia, per quam omnia aequabantur in homine, homo necessario mortuus fuisset".

"Praeterea, quandiu portio superior ipsius animae perfecte obediebat Deo tandiu omnes vires inferiores in homine de iure debuerunt superiomibus obedire: sed talis obedientia virium inferiorum ad superiores in primo homine non potuit esse sine originali iustitia: ergo, etc.".

"Homo autem sine originali iustitia, quantumlibet pure creatus, sensisset immediate bellum virium inferiorum contra superiores propter diversitatem suorum appetituum... ideo indiguit originali iustitial..," (Ibi $\bar{d}$., concl. 1 , solutio ad instantiam). 
"Originalis autem iustitia dicit perfectam anima rectitudinem" 31.

Dirigía todas las potencias humanas, racionales, sensitivas y naturales. Regulaba las funciones del cuerpo, haciendo que el hombre no llegara a morir. Sostenía en el recto orden todas las potencias del alma, preservándole así de cometer pecados. Ordenaba la voluntad y el entendimiento. Regulaba los apetitos de la carne y de las potencias inferiores, fieles siempre al dictamen de la razón ${ }^{32}$.

Recibe el apelativo de original, porque Adán, como cabeza de toda la humanidad, debía haberla transmitido a todos sus descendientes, en caso de no haber pecado ${ }^{33}$.

Este don de la justicia original "primo et per se" radicaba en el alma, como sujeto de dicha justicia; secundariamente, radicaba y fluía, como por redundancia, en sus potencias.

“...sed originalis institia, cui originalis culpa opponitur privative, mincipaliter fundabatur in essientia animae, et per redundantiam in potentiis" 34.

2. La pérdida de dicha justicia por el pecado cometido por nuestros primeros padres en el paraiso al desobedecer a Dios.-La posesión y continuación del hombre en el estado de la justicia original estaba vinculado a su obediencia a un precepto del Señor. Al transgredir Adán este mandato, quedó privado para siempre de la justicia original.

"...Adam ratione sui delicti perdidit originalem iustitiam..." 35.

Habiendo excluído de la justicia original la gracia santificante o

31 In 2 Sent., d. 21-32, q. 1, a. 4, concl. 1, 1.

32 "Praeterea, sicut ipsa originaliss iustitia manens in homine ipsum praeservasset ab omni corporali infirmitate; sic multo magis ab omni spirituali...".

"Praeterea, nulla existente deorldinatione virium inferiorum respectu superiorum nullum poterit esse peccatum veniale; sed antequam homo inobediens esiset Deo, et deordinatuis ab eo per peccatum mortiale, non potuit esse aliqua deordinatio virium inferiorum a supperioribus'" (Ibid., concl. 1, 2-3). Cfr. Ibid., concl. 1, ad 1-3; Ibid., d. 28-29, q. 1, a. 3; Ibid., d. 19, q. 1, a. 4 .

33 "... quia per malitiam perdidit originalem iustitiam, quam in suos posteros origninaliter transfudisset, si ipisam non perdidisset..." (In 3 Sent., d. 19-20, q. 1, a. 4, concl. 1 , aid. 1).

"... sicut Adam acclepit a Domina originglem iustitiam non solum ut in se erat persona particularis, sed etiam ut erat principium ceterorum..." (In 2 Sent. d. 30-31, q. 1, a. 3, concl. 1, ad 1). Cír. además, Ibid., a. 1, concl. 1, ad 2; Ibid. a. 3 , concl. 1 , ad 5 .

34 In 2 Sent., d. 30-31, q. 1, a. 4.

36 Ibid., a. 1, concl, 1, ad 2. Cfr. Ibid, a. 3, concl. 1, ad 5 . 
gracia "gratum faciens", es claro que no se debe hablar de carencia o pérdida de ésta. Pero la gracia "gratis data" ${ }^{36}$ con todo el séquito de cones que poseía Adán en el estado de inocencia, por su pecado quedó para siempre perdida.

Tomás de Argentina no se entretiene en estudiar la existencia de este pecado. Es una verdad revelada y como tal la acepta. Sin embargo investiga sus causas. Le resulta extraño que en un estado de orden y perfección tan ilimitados haya podido ocurrir desgracia tal. Y culpa al demonio, por su seducción y tentación, de haber engañado al hombre ${ }^{37}$.

Pero esta tentación o engaño de Satán en nada disminuye y disculpa la voluntariedad del pecado de Adán, quien personalmente y por propia voluntad desobedeció al precepto divino.

“...in Adam fuit culpa proprie personalis, quia personali suo actu, et propria voluntatie fuit perpettratum; ...quia Adam acitu proprio et sua voluntate pecclavit..." 38 .

Si en algo pudiera disculpar a Adán la ignorancia, más bien sería en la serie de pecados que se relacionan y siguen a este primero. Pero en su primera rebelión contra el precepto divino, ninguna clase de ignorancia pudo excusarle de su mal y del consiguiente castigo ${ }^{39}$.

36 La diferencia entre ambas gracias está expressada por nuestro autor en estois términos: "... essse gratiss dartum sit commune omni gratiae; tamen quia quaedam est gratia, quae formaliter facit nos gratos Deo, et per consequens ex suo effectu formali vindicat sibi nomen proprium, et dicitur gratia gratum faciens: ideo hoc nomen commune, quo dicitur gratia gratis data, remanet tanquam proprium pro altero extremo contradictionis, puta pro omni gratia, quae non facit formaliter Deo gratum". (In 4 Sent., d. 2, q. 2 , a. 2 resiponsio ad instantias). Cfr. In 2 Sent., d. 4-5, q. 1, a. 2; Ibíd., 'd. 21-23, q. 1, a. 1, concl. 1, ad 3, Ibid.. d. 26-27, q. 1, a. 1, concl. 1, et ad rationem Durandi.

37 "Secunda conclusio est, quod tentatio hominis in praradiso non fuit a carnali complexione, sed ab ipso daemone, quia ubi omnia intrinseca sunt ordinatissime idisposita, ibi pars partem non impugnat, sed adiuvari; ... sed ratione originalis iustitiae in statu illius innocentiae omnia hominis interiora fuerunt ordinatissime disposita; ergo nulla ab intrinseco tali homini potuit esse pugnai. Quod autem fuerit extrinsiecus a daemone, patet de serpente, in cuius figura apparens daemon, primo tentavit mulierem, tanquam ipartem infirmiorem, et deinceps virum per mulierem tanquam partem fortiorem (In 2 Sent., d. 21-23, q. 1, a. 2, concl. 2).

38 In 2 Sent., d. 30-31, a. 1, a. 2. En otro lugar del mismo artículo escribe: “... peccatum originale est quassi quoddam medium inter acticalem culnam insius Adae, a qua causatur, et culpam nostram causalem, quam causat, quorum extremorum utrumque est voluntarium..." (Ibid., ad: 4, praeterea).

39 "Prima est, quad quamvis peccaverint igmorantest..: primo tamen suo pecicato non pedcaveruint ex ignomantia, ita quod ignorantia esselt carsa primi sui peccuti. nam poena non praecedit peccatum, sed sequitur...".

"Secunda conclusio est, quod quoad altio pecala quaie sequebantur primum preacatum, ipse prius homo aliquo modo pecslavit ner. nesichentilwm, ner innorantiam, per errorrem, aic pier infidielitatem. Ista enim sic se habent per ordinem 
A pesar de la enormidad del pecado de soberbia de Adán y de las funestas consecuencias que originó, pudo Adán, sin embargo, alcanzar la remisión y perdón deil mismo. Dios no le privó de los auxilios y gracias divinos que le ayudaran a aborrecer el pecado, mientras permaneció en esta vida terrena ${ }^{40}$. Pero jamás consiguió Adán, a pesar de su dolor y arrepentimiento, restituir a la naturaleza humana el estado primitivo de justicia que él había tenido. Los méritos de su penitencia sólo le pudieron aprovechar a él, mientras su pecado ocasionó la ruina de sus descendientes, que quedaron privados para siempre de la justicia original. Esta le había sido otorgada como principio y cabeza de la humanidad y, como tal, fue privado de ella por su pecado.

“...ipse Adiam bonum suae poienitentiale nom plotuit in posteros tramsfundlere: quia 'principium talis boni fuit gratia ipsi a Deo personaliter et ut privatae personae data; malum autem originalis culpae fuit in eo, ut erat principium ceterorum: sicut etiam eius oppositum, scilicet originalis iustitia fuit sibi data, tamquam universali et originali principio, a quo transfunderetur in posteros. Quam quidem iustitiam, cum perdidit, non solum pro se, sed etiam pro omnibuis aliis eam perdidit, quia eo tenore, quo eam recepit, eodem tenore eam perdidit, et per consequens tali perditione infecit humanam naturam, non solum ut in se personaliter fuit, sed ut in omnes alios originaliter transfundenda erat" 41.

3. La transmisión de ese pecado, llamado original, a todos sus descendientes.-El don de la justicia original le fue concedido a Adán como cabeza y principio de todos los hombres. De no haber prevaricado, los privilegios y gracias de este estado se hubieran transmitido a todos

auod semper illud quod sequitur, includit praecediens". (In 2 Sent., d. 21-23, q. 1, a. 3. inquisitio 3 , concl. 1, 2).

40 "... plecclatim primi hominis ercat remissibile ex hoc quod per Diei misericordiam rorimus homo de suo peccato potuit poenitere; quia agens liberi arbitrii, quandiu est, in vita, potest habere dislplicentiam de malo, et ner consequens divina bonitate cooperante potest agere poenitentiam de peccatis, et conslequi gratiam Dei; sed primus homo, postiquam primum peccatum perpetravit, remansit in via et non erat inmediate in termino; quia post mortem a nrimo tunc erit in termino: ergo mediantibus divinis impertibus et impulsionibus potuit habere sui peccati displicentiam. et per conseauens Dei bonitate cooperante potuit agere condignam poenitentiam". (Ibid., a. 1, concl. 2).

. 41 In 2 Sent.. d. 30-31, a. 1, a. 3, concl. 1, ad 5. En otro lugar escribe: "... posito quod Adiam ide conguru potuerit elicere actum bonitate intensiva aequipollentem malitiae peccati sui, nullum tamen potuit elicere actum aequivalentem bonitate extensiva malitiae sui peccati: quia per malitiam perdidit originalem iusititiam; ouam in suos nosteros originaliter transfudissiset, si ipisam non perdidisset. seed per nullam bonitatem cuiuscumque sui actus potuit acauirere gratiam seu virtutem. ouam transfunderet in suos posteros loco originalis iustitiae, quam pro se et pro ipsis perdidit universaliter..." (In 4 Sent., d. 19-20, q. 1 , a. 4, concl. 1 , ad 1). 
sus descendientes. Pero Adán pecó. Con su rebelión al precepto divino perdió la justicia original para él y para toda su descendencia. Todos los hombres se hicieron en él y con él deudores de la justicia original y, por tanto, reos de pecado. Todos los hombres que descienden de Adán jor vía de generación contraen la mácula original.

"De lege communi ariginale peccatum universaliter transfunditur in omnes homines, qui seminaliter descendunt ab Adam...

Praeterea, tota natura fuit infecta in Adam: ergo omnes, qui humanam naturam naturalitir seu modo naturali $a b$ Adam sumpserunt, ipsam infectam acceperunt, quantum esti de lege communi" 42.

La existencia del pecado original en todos los descendientes de Adán, desde el principio de su existencia, es una verdad que se impone. Las fuentes de la revelación lo atestiguan suficientemente, por lo qur todo católico debe admitirlo.

"Quilibet catholicus habet concedere, quod aliquod peccatum homo incurrat ab origine suae concepitionis" 43.

El pecado original reviste ciertas características de voluntario. No se trata de un pecado actual, cometido por voluntad propia. Es un pecado natural, original, pero también voluntario, ya que todos pecamos en Adán, cabeza física y moral de la humanidad. Basta tener la misma naturaleza para ser partícipe de ese pecado. La razón fundamental y última de la voluntariedad del pecado original en los descendientes de Adán, se funda en la solidaridad física con él.

"...nos ommes fecimus illud malum in Adam secundum quod omnium nostrumi natura in ipso fuit unita, cum hoc peccaltum plerporetravit" 44.

42 Ibid., concl. 1. Cfr. además, Ibid., ad 1, 5; Ibid., a. 1, ad 2.

Sobre esta doctrina del pecaido original, su esencia, transmisión, etc., según Tomás de Argentina, efr. G. Tummrcello, o. c., 5-10; G. Df́az, o. c., 95-131 rasisim.

43 Ibid., a. 1, concl. 1. Nuestro autor recogé aquí una serie de testimonios de la Sagrada Escritura -Pis. 50, 7; Rom. 5, 12; I Cor. 15, 21-22; Hpin. z. o-, Tradición y Magisterio Eclesiástico para probar su afirmación. Cfrr. también Ibid.. a. 3 , concl. 1 .

44 In 2 Sent., d. 30-31, q. 1, a. 2, ad 1. El "Doctor Fácil” recurre a varios ojemplos para probar esta voluntariedaid y solidaridad. Así, por ejemplo, escrive: "...sicut manus, per quam committitur" homicidium, in se consideraita non est culpabilis: eo quod motus suus non fuit praecise a se, sed ad imperium alterius. sciliceit ipsius voluntatis: ut tamen est pars hominis, qui voluntaris commisit homicidium, sic verel dicitur culpabilis, et a iusto iudice punitur et mutilatur; sic quamvis quilibet singularis homo in se personaliter consideratus 
Por otra parte, el pecado original podemos denominarlo voluntario por el hecho de que nos inclina a cometer voluntariamente el mal ${ }^{45}$.

Por el hecho de ser voluntario, la mancha original ocasiona en nosotros un reato de culpa y de pena ${ }^{46}$.

Primeramente el pecado original tiene razón de culpa en el verdadero y propio sentido. Pero esta culpa es distinta en Adán y en sus descendientes. En Adán es propiamente culpa personal: por su voluntad y libre elección prevaricó. En su descendencia, sin embargo, es una culpa natural : la naturaleza humana comunicada por Adán a sus descendientes se hizo culpable en el primer hombre y sigue siendo culpable en todos los que le siguen.

\footnotetext{
"Peccatum originale proprie loquendo potest dici culpa, aliter tamen in ipiso Adam, et aliter in ceteris hominibus: nam in Adam fuit proprie culpia. personalis, quia personali suo actu et propria voluntate fuit perpetratum; sed in aliis suis posteris fuit et est culpo naturatis, eo quod natura per Adam in posteros transfundenda, in ipso Adam culpabiliter effecta, cum huiusmodi culpa ad posteros derivetur. Quantum enim ad istum peccatum est quodiammodio modus oppositus in Adam et in nobis: nam quia Adam actu proprio et sua voluntate peccavit: ideo primo fuit infecta persona, et per infectionem personae fuit infecta natura sed in nobis primo est infecta natura ab infecta persona ipsius Adae per seminalem propiagationem transfusa, et per consequens persona cuiuslibet nostrum in tali natura infecta constituta idicitur esse culnabilis, et maculata" 47 .
}

Las penas que se derivan y trae consigo la culpa hereditaria -como

non sit culpabilis, ut tamen recepit ab eo, qui eam depravavit, et eam sua voluntate voluntarie maculavit; sic quilibet homo est ailiquo modo voluntarie culpabilis" (Ibíd., ad 3).

En opinión de G. DfAz esta concepción de Tomás de Argentina es "esencialmente dinámico-activa" (O. c., 105).

45 "Sicut habitus vitiosus dupliciter dicitur voluntarius, uno modio, $\infty$ quod voluntarie a mala voluntate est introductus; alio modio, quia ad malam voluntatem inclinat; sic pecceatum originale potest dici voluntarium, tum quia a mala voluntate primi hominis est introductum, tum quia nos ad malam voluntatem inclinat" (Ibid., ad 4). Cfir. In 2 Sent., d. 40-41, q. 1, a. 3, concl. 1, ad 1 .

46 Según Tomás de Argentina reatus es "id quo iuste quis tenetur obnoxius" (In 2 Sent., d. 30-31, q. 1, a. 2 contra opinionem 2). Y en otro lugar: "reatus est obligatio ad! poenam ratione perpetrati sceleris seu delicti" (Ibid., d. 42 . q. 1 , a. 3 ).

47 In 2 Sent., d. 30-31, q. 1, a. 2. Ein el mismo artículo escribe el Argentinense arguyendo contra la opinión de Abelardo y Durando de Saint-Pourcain, que afirmaban que la mácula original en nosotros no es imputada a culpa, sino a pena: "licet ex hoc, quod peccatum Adae non potuit traduci in nos quoád actum, bene arguatur quod tale peceatum non sit in nobis: personalis culpa; ex hoc tamen non habetur quin possit dici naturalis culpa" (Ibidi., ad 2). 
dice nuestro autor, "omnis poena praesupponit culpam" 48 - son muy variadas. $\mathrm{Y}$ según sea su cualidad e importancia, así son más o menos participadas por cada uno de los descendientes de Adán. Tomás de Strasbourg distingue entre penas que se siguen "per se et directe" y penas que derivan "indirecte et per accidens" del pecado original. Las primeras (privación de la justicia original, carencia de la gracia divina y privación de la visión de la esencia divina) son infligidas a todos los hombres; las segundas (muerte corporal, enfermedades, pasiones, concupiscencia) son participadas en mayor o menor grado. $\mathrm{Y}$ añade: no hemos de culpar a Dios de esta desigualdad ${ }^{49}$.

En cuanto a la esencia y modo de transmisión del pecado original, es digno de notar la orientación marcadamente "sentenciaria" y "anselmiana" de la doctrina de Tomás de Strasbourg.

Entre los escolásticos de los siglos xII y xiII dos corrientes teológicas intentaban explicar con acierto la esencia del pecado original: la corriente que suelen llamar agustiniana, seguida preferentemente por Pedro Lombardo y los sentenciarios, según la cual el pecado original consiste en la concupiscencia ${ }^{50}$, y la anselmiana, de la que sería princi-

4.8 Ibid., d. 35-36, q. 1, a. 4 concl. 1.

49 "Breviter dico quold aliquae poenae peceati originalis sunt per se et primo inflictae ratione talis peccati, et istae sunt aequaliter in omnibus, in quibus reginat tale peecatum, puta privatio iustitiae originalis, carentia divinae gratiae et carentia visionis divinae essentiae. Alias autem sunt poenae indirecte, quae consequuntur ipsum originale peccatum per accidens, puta sicut causam removentem prohibens: et huiusmoidi poenas non oportet essise aequales: in singulis: tales poenae sunt mons corporalis, infirmitas et ceterae passiones, et pronitas ad peccadum: quae omnia contingunt in nobis ex rebellione virium inferiorum ad superiores, et haec rebellio accidit ex remotione originalis iustitiae, ut patuit superius. In hac tamen inaequalitate iustitia iudicis, scilicet Dei, non est increpanda: nam sicut iudex humanum propter aequalem delictum commissum a duobus ambois privansi oculis non est calumniandis, si consequenter unus illorum propter carentiam oculorum frangit tibiam, et non alter: quia talia per accidien is consequuntur: sic in proposito, etc." (In 2 Sent., d. 32-33, q. 1, a. 1) 50. Muchos autores meldievales $\mathrm{y}$, en especial, algunos comentadores de las Sentencias, haciendo hincipié en varios textos de iSan Agustín, donde el santo resalta la concupiscencia, hicierón consistir en ésta la esencia del pecado originai, atribuyendo falsamente a San Aguistín - de ahí el nombre de agustiniana - una doctrina que él no defendió.

Más tarde el movimiento protestante se hizo eco de esta corriente doctrinal y, apoyándose de nuevo en San Aguistín, fue adiquiriendo mayor preinonderancia. Mordernamente, sin embargo, la cuestión ha vuelto a ponerse sobre el tapete de la discusión.

Entre losi autores que hablan de la concupiscencia como esencia del pecado original en la concepición agustiniana podemos enumerar a E. BuonaIUTi, en su primera época, en su estudio "Agostini e la colpa ereditaria": Rỵhemche religiose 2 (1926) 160 sis., publicado en Saggi di Storia del Cristianesimo, Vicenza 1957, 303-325; A. PINCHERLe, La formazione della dottrina agostiniana diel peccato originale, Cagliari 1938. En el campo protestante es digno de mención 
pal defensor Santo Tomás de Aquino, que hacía consistir el pecado original en la privación de la justicia original, con el débito de tenerla. Tomás de Argentina, conociendo ambas corrientes, es, en opinión de Tumminello ${ }^{51}$, uno de los teólogos que trata de conciliarlas entre sí. De ahí que su doctrina en torno a la esencia del pecado original aparezca un tanto oscura y difícil de comprender a primera vista.

Tomás de Strasbourg, como varios teólogos de su tiempo, distingue dos elementos en la culpa hereditaria: el elemento material y el elemento formal.

El elemento formal, que constituye la esencia del pecado original, deriva de la concepción anselmiana de éste ${ }^{52}$. Por eso la definición de pecado original, considerado en su esencia, está propuesta por el "Doctor Fácil" en estos términos: "peccatum originale non est aliud, secundum suum esse formale, quam carentia iustitiae originalis cum debito habendi eam". Son muchos los lugares en que el Argentinense nos ofrece esta clásica definición. Así por ejemplo, escribe:

"Sed quia Adam, ratione sui delicti perdidit originalem iustitiam, quam sic a Deo accepit, quod per ipsum talis iustitia in posteros debebat transfundi: ideo de iure omnes posteri de ea sunt privati. Et quia peccatum originale non est aliud quam carrentia originailis iustitiae cum diebito habendi eam: ideo omnes posteri secundum legem communem, qui seminaliter descendunt de Adam, nascuntur cum peccato originali" 53.

"Originalis culpa formaliter accepta opponitur privative originali

J. Gross, "Das Wesen dier Erbsúnde nach Augustin": Augustinus Magister, II, París 1954, 773-787.

Eis, sin embargo, mucho mayor el número de autores que niegan tal concepción agustiniana. Así, v. g'r., N. CoNCETTI, Esamen della genesi della dottrina agostiniana intorno ail peiciato originale di E. Bonaiuti Fermo 1922; H. DEL VAL, Theologia Dogmaticai I, EI Eiscorial 1926, 59.0-593, 605-612; J. LE BLIC, "Le peché originel selon Saint-Augtustin": Rech. scien. melig. 16 (1926) 97-119; 17 (1927) 414-433; M. Merdin, Saint Augustin et les dogmes du peché orioinel et die la gracle, París 1931.

Un estudio moderno sobre la concepción protestante del pecado original escrito por un convertido y digno de tener en cuenta es el de W. H. VAN DE POL, Das meformatorische Christentum, Einsiedieln 1956. Cfr. F. MorIoNES, Enchiridhon theologichum S. Augustini.

51 G. TUMMINELLO, o. c., 6.

52 "Si Deus non damnat hominem nisi propter iniustitiam, damnat autem aliquem propiter originale peccatum, engo est aliud originale peccatum quam iniustitia. Quod si ita est, et iniustitia non est aliud quam absentia debitae iustitiae, nom enim videtur esse iniustitia nisi in natura, quae cum debet habere iustitiam, non habet, utique originale peccatam clauditur sub eadem definitione iniustitiae" (S. ANSELMUS, De concieptione virginali et originali pelccato, c. 3: PL. 158, 436). Cifr. Ibid., c. 5, 22, 29 : PL. 158, 429, 453, 462-464; J. B. KoRs, La justicie primitive et le pieché originel d'aprés S. Thomas, Kain, Belgique 1922, 39 ss.

53 In 2 Sent., d. 30-31, q. 1, a. 1, concl. 1, ad 2. 
iustitiae: quia culpa originalis non est aliud secundum suum esse formale, quam carentia iustitige originalis cum debito habendi eam, et tamen originalis iustitia, cum sit quaedam habitus, oportet, quod habeat rationem primae perfectionis" 54

Esta privación o carencia de justicia implica un doble defecto: uno en la esencia del alma y otro en sus potencias. Como la justicia original, así el pecado del mismo nombre "primo et per se" radica en la misma esencia del alma y, por redundancia, en sus potencias.

"Peccaitum originalle principaliter et pier se est in essemtia animale, per quamdam tamen redundantiam est in omnibus potentiis animae..." 55.

El pecado original no puede radicar en la carne, que no es susceptible de culpa formal ${ }^{56}$.

54 In 3 Sent., d. 19-20, q. 1, a. 1, concl. 1, ad 2. Cfr. Ibid., ad 3; In 4 Sent. d. 3 , a. 3 ad solutionem rationum secundae opiniones, donde esicribe: "...quia deformitas peccati originalis, de qua ad praesensi loquimus, opponitur originali iustitiae, ...nam peccatum originale est carentia originalis iustitia cum debito habendi eam".

Nos place recoger las afirmacioness de A. GAUDEL sobre la doctrina de Tomás de Strasbourg" acerca del pecado original: "Pour Thomas de Strasbourg dans son Commentaire des Sentences, le peché originel esit bien une culpa naituralis et non simplement un reatus poenae; la privation ide la justice originelle n'en constitue pas l'essence, mais plutot une consequence, le fomes, cause de chaque peché actuel. (Ibid., d. 35-36, a. 2). ("Peché Originel: D. T. C. XII/1, París 1933, 495-496.)

Juzgamos completamente errónea esta interpretación, en lo que se nefiere a la esencia del pecado original, como puede fácilmente vense a la luz de los textos que hemos ofrecido. Más aún, en el primer texto que aduce A. GaudeL, Tomás de Strasbourg afirma bastante explícitamente que la privación de la justicia original es essencia de tal pecado, yiai que está enumerada entre las consecuencias' o penas que per se et ratione talis peccati son inflingidias a los descendientes de Adán, mientras que la concupiscencia o fomes = pronitas ad peccadum, está enumerada entre las penas o consecuencias que se siguen per accidens.

En cuanto a la segunda cita de A. GAUDEL, hemos de afirmar que, dispués de releer el artículo por él indicado, sólo hemos encontrado un lugar donde el Argentinense emplee la palabra fomes o su equivalente. Pero de ningún modo asesora la afirmación de A. GAUDEL. Dice así el texto: "Respondeo quod non est simile: quia habilitas ad malum, puta fomes peccati fundatur in natura sensibili, et non in natura perpetua,' nec fuit a principio institutionis naturae, sed solum incepit esse tempore destitutionis naturae: ideo minorem habet stabilitatem, quam habilitas ad bonum, quare radicata est in natura perpetua et ab ipso creatore cepit esse a principio institutionis naturae" ( $L$. c., a. 2 solutio ad instantiam secundam).

G. DíAZ, o. c., 127, not. 75, enumera algunos teólogos ag’ustinos según los cuales Tomás de Árgentina define el pecado original por la concupiscencia y por la "qualitas morbida".

55 In 2 Sent., d. 30-31, q. 1, a. 4 “...secus est enim de culpa originali, quae homo advenit sine proprio actu; illa enim primo inficit essentiam animae et mediante essentia inficit potentias" (In 4 Sent., d. 2, q. 2, a. 2, concl. 2, ad 2).

56 "In nullo genere caustae proprie loquendo caro potest dici causa originalis peccati, nam licet a protoplasto huiusmodi defectus descendant in nos per carna- 
El elemento material del pecado original es la concupiscencia ${ }^{57}$. Existen, sin embargo, textos donde Tomás de Strasbourg afirma que el pecado original no es otra cosa que la concupiscencia habitual, el "fomes", causa de todo pecado ${ }^{58}$. Debemos, pues, interpretar estos textos a la luz de los citados anteriormente al hablar del elemento formal o de la esencia del pecado original y de la radicación en el alma y sus potencias..

Siendo doble el apetito, a saber, sensitivo y racional, hemos de distinguir en el pecado original un doble elemento que se refiera y abarque a ambos. Uno que tenga su sede en el apetito sensitivo: es el elemento material, la concupiscencia. Otro en el apetito racional: la privación o la carencia de la justicia original con la obligación de tenerla, que es el elemento formal del pecado original. Podemos, pues, denominar el pecado original bien por su elemento formal, o por su elemento material. $\mathrm{Y}$ en este último sentido se puede decir que el pecado original es la concupiscencia de la carne.

Otro argumento para probar que la concupiscencia, como tal, no es la esencia del pecado original se deduce de la doctrina sobre los efectos del bautismo. Tomás de Argentina afirma que la culpa original y la gracia sacramental del bautismo se oponen entre sí ${ }^{59}$, pero aún permanece en el regenerado el vicio de la concupiscencia o del "fomes peccati", que de alguna manera es refrenado.

"Triplex videtur esse effectus' gratiae baptismalis: nam per gratiam baptismi fomes peccati alliqualiter refrenatur, culpa exmurgaitur, et mens illuminatur" 60.

Por el bautismo se remite toda razón de culpa original, en cuanto que por la gracia bautismal nos hacemos miembros de Cristo y se nos

lem concupiscentiam, tamen in ipso genito non habet rationem peccati donec pertingat ad animam". (Ibid., d. 32-33, q. 1, a. 3, concl. 1, ad 1).

57 Nos referimos a la concupiscencia habitual, que deriva del pecado original, denominada tamibién por nuestro" autor fomes peccati, pronitas ad peccandum, libido, habilidas ad malum, y que él define así: "fomes est quaedam inordinata concupiscentia appetitus sensitivi seu rebellio virium inferiorum ad superiores ex oxiginali peccatio procedens" (In 3 Sent., d. 3, q. 1, a. 3-4).

58 "Peccatum originale sumptum cum excluisione omnis actualis peccati solum dicit concupisicentiam habitualem" (In 2 Sent., d. 32-33, q. 1, a. 3, conc. 1, 3).

59" "Alio modo, cum ad liberalem infusionem Spiritus Stancti peccatum originalem dimittitur" (In 4 Sent., d. 6, q. 1, a. 4, concl. 1, nota).

60 Ibid., d. 3, q. 7, a. 4. "Quia fomes peccati, qui inclinat in actus vitiosas, licet aliquo modo virtute baptismi diebilitetur, tamen non plene ligatur, nec totaliter extirpatur" (Ibid., d. 4, q. 1, a. 2, concl. 1, ad. 4). 
perdona el débito de poseer la justicia original. Si continúa en nosotros la concupiscencia, la inclinación hacia el pecado, es porque no constituye el elemento formal del pecado original.

La culpa original, según el Argentinense, se transmite por medio de la generación ${ }^{61}$ dominada por la concupiscencia habitual o "fomes peccati". Aunque pudiera darse el acto conyugal sin el deleite carnal actual y concupiscible, el pecado original se transmitiría igualmente, puesto que en dicho acto siempre existe la concupiscencia habitual o fomes, que deriva del pecado original y que es, además, el que ocasiona la infección en la nueva prole.

“...dato per impossibile, vel possibile, quod in actu generationis alicuius hominis nulla esset libido actualis; esset tamen in eo libido et concupiscentia habitualis, quae est derelicta in eo ab ipso peccato originali, quae dicitur fomes peccati, ratione cuius generaret prolem infectam peccalo originali" 62.

Aunque el pecado no puede radicar en la carne, como antes indicamos, porque ésta no es susceptible de culpa, sin embargo, Tomas de Strasbourg, siguiendo las huellas de la corriente doctrinal sentenciaria ${ }^{63}$,

61 "De lege communi originaliter peccatum univensaliter transfunditur in omnes homines qui seminaliter descendunt ab Adam" (In 2 Sent., d. 30-31, q. 1, a. 3, concl, 1).

"Originale peccatum transfunditur" per patrem in prolem per se loquendo" (In 4 Sent., d. 6, q. 1, a. 4, concl. 3 , contra rationem 2 ).

62 In 2 Sent., d. 30-31, q. 1, a. 3, concl. 1, ad 9.

63 Juzgaba $P$. Lombardo que el pecaido original no es otra cosa que la concupiscencia o concupiscibilidad, la cual no era un acto, sino un vicio: "Quid ergo originale peccatum dicitur? Fomes peccati, scilicet concupiscentiam vel concupiscibilitas: quae dicitur lex memibrorum... Nomine autem concupiscentiae non actum concupiscendi, sed vitium primum significavit... Ex his datur intelligi, quid sit originale peccatum, scilicet vitium concupiscentiae...".

La concupisicencia de la carne es transmitida a los hijos con la carne misma, se mancha y se corrompe. Como la carne se propaga en los hijos com aquella corrupción y vicio, el alma, cuando es infundida (a los 40 u 80 días de la generación), contrae por el contacto con la carne la malicia y corrupición del pecado: "Unde caro ipisa quae concipitur, in vitiosa concupiscentia pollitur et corrumpitur: ex cuius contactu anima cum infunditur, macula trahit, qua pollitur et fit rea, id est, vitium concupiscentiae, quod est originale peccatum".

Aunque este vicio o corrupción de la carne no puede llamarse culpa si sólo se considera en la carne, es, sin embargo, raíz y causa de la culpa original, sólo inherente en el alma como en sujeto, puesto que la carne separada del alma es irracional y ninguna substancia irracional puede ser sujeto de culpa: "Ideoque ipsum peccatum dicitur manere in carne. Caro ergo quae in concupisicentia libidinis seminatur, nec culpam habet, nec actum culpae, sed causam. In eo ergo quod seminatur, corruptio est; in eo autem quod nascitur, concupiscentiae vitium est". (P. Lombandus, Siententiarum libri quajituor, 1, 2, d. 30.) Cfr. J. B. KoRs, La justice primitive et le péché originel d'apres S. Thomas, Kain, Belgique 1922, 55-60; A. Gauded, "Péché omiginel": D. T. C., XII/1, París 1933, 455-458. 
repetidas veces afirma que el instrumento de la transmisión del pecado original es la carne infeccionada, que a su contacto con el alma, al ser ésta infundida, la mancha y corrompe.

"Instrumentum pecqati Adqe, puta, insw infecta caro in utero attindit animam rationalem, qua huiusmodi caro informatur" 64.

"...quia caro propria est immediata causa infectiomis animae, quae infunditur taili carni...65.

Tomás de Argentina hace, además, mención de una "qualitas morbida", que infecciona el semen y lo corrompe moralmente, siendo ocasión de la culpa hereditaria. Sin embargo, parece que esta "qualitas morbida" no es la concupiscencia, sino una propiedad especial del semen ${ }^{66}$, contraída por el pecado original.

"Deus potuit semen, a quo Virgo propagata est, praeservare a qualitate morbida, ex cuius conexione foetusi inficitur originali macula... Sicut enim in paradisso fuissent geniti homines sine originali peccato propter puritatem seminis, et carentiam huius morbidae qualitatis, sic...; sed semen est naturaliter prius illa morbida qualitate contracta ex peccato primi hominis..." 67.

Según esto, tendríamos que el pecado original se transmite por la generación natural de este modo: la libido o concupiscencia habitual, que se da siempre en el acto conyugal y proviene del pecado hereditario, origina en el semen una "qualitas morbida". Esta ocasiona la corrupción e infección de la carne, que, a su vez, infecciona y contamina el alma, cuando ésta es infundida en el cuerpo. Concepción que sintéticamente está contenida en estas líneas:

"...licet in carne non sit peccatum formaliter, est tamen in ea virtualiter: carro enim illa infection et polluta ex immuindo semine cum libidine conclepta est illius conditionis, quod sic inficit animam, quae sibi infunditur, quod vires sensitivae in partibus illius carnis fundatae non obedinnt plene superioribus viribus ipsius animae, et per consequens est ibi exclusio originalis iustitiae, ratione cuiusı vires inferiores plene et perfecte obediebant superioribus, et per oppositum in talli anima erit originalis macuila" 68.

64 In 4 Sent., d. 6, q. 1, a. 4, concl. 3, ad 2.

65 Ibid., contra rationem.

66. Según G. DíAZ, o. c., 71, se trata de una propiedad física del semen.

67 In 3 Sient., di. 3, q. 1, a. 1, concl. 1 .

68 In 2 Sent., d. $30-31$, q. 1, a. 1 , conel. 1 , ad 3. 
4. La excepción de contraer la mácula original, hecha por Dios a Maria, precisamente en atención a la singular misión a que la tenia destinada.-En este cuarto punto es en el que pondremos especialmente nuestra atención. Hemos indicado y tratado someramente los otros tres, ya que propiamente no entran de lleno en nuestro intento, si bien les consideramos entre sí y necesarios para resolver con acierto y entender más fácilmente la singularidad del privilegio mariano de la Inmaculada.

Doctrina Inmaculista.-Tomás de Argentina en el Commentarium in II Librum Sententiarum, distinción XXX-XXXI, art. 3, se pregunta si el pecado original se transmite comúnmente a todos los hom$\mathrm{b}_{1}{ }^{69}$. Y su respuesta es clara y tajante. La hemos oído en las páginas anteriores: se transmite a todos los que por generación natural descienden de Adán, pero por privilegio especial está exceptuada María.

\footnotetext{
"Prima (conclusio) est, quod de lege communi originale peccatum universaliter transfunditur in omnes homines, qui seminaliter descendunt ab Adam.

Secunda est, quod de privilegio specciali ista macula non tetigit Virginem gloriosam" 70 .
}

Doctrina que recalca de nuevo en el mismo artículo al responder a las objecciones ${ }^{71}$, y al enunciar por segunda vez la conclusión en la que afirma el privilegio inmaculista. Afirmación, cuya veracidad y alcance doctrinales promete avalorar con varias pruebas y en el debido lugar, para que no corra el riesgo de ser negada tan gratuitamente como él la ha enunciado.

\begin{abstract}
"Secundo dico, quod Virgo gloriosa ex privilegia singulari sic fuit praerventa Spriritus Sancti gratia, quod originali culpa numquam extitit maculata. Hane tamen conclusionem cum sua probatione et declaratione, ne nimis ad praesens teneam, differo usque ad tertiam distinctionem tertii libri Sententiarum: ibi enim proprie locum habet" 72 .
\end{abstract}

El estudio de las perfecciones con que María fue adornada en el

69 "Utrum peccatum originale omnibus hominibus generaliter infundatur". (In 2 Sent., d. 30-31, q. 1, a. 3).

70 Ibid., conel. 1 et 2 .

71 "Sed ista non concludunt: quia excento filio Virginis et Viranime Genitrice, de aliis hominibus concorditer tenetur ab omnibus catholicis doctoribus quod concipiantur in peccato originali.". (Ibid., contra obiectiones.)

72 Ibid., concl. 2 . 
instante de su ser, de la santidad que llevaba consigo el misterio de la Inmaculada, lo hace el "Doctor Fácil" relacionando este misterio con la Maternidad divina. Porque en fin de cuentas, si en ese primer momento se le concedió la gracia o gracias singulares que recibió, fue en previsión de dicha Maternidad. Así pues, una mayor comprensión de las gracias de la Maternidad, que termina en el Hijo Dios-Hombre, nos lleva a otra mayor comprensión del contenido sobrenatural del privilegio concepcionista. De ahí la íntima conexión y concatenación de ideas que se traduce en ordenación sistemática de las cuestiones teológicas: preparación a la Maternidad divina, Maternidad divina y fruto de esa Maternidad, o sea, Cristo Dios-Hombre. Por tanto, el lugar apropiado para exponer el privilegio singular de la concepción inmaculada de María es el Comentarium in III Librum Sententiarum, al tratar del misterio del Dios-Hombre, es decir, del Verbo encarnado.

Tomás de Argentina propone la cuestión en la distinción III. Y, como lo hicieran Guillermo de Ware, Juan Duns Scoto, Guillermo de Nottingham, Aufredo Gontier, Pedro Aureolo, Francisco de Mayron, Juan de Bassolis, etc., la propone con precisión y sencillamente: "An Beata Virgo fuerit concepta in peccato originali."

La solución está expresada en las dos fórmulas de exposición del privilegio: una negativa (exención de todo pecado original) y otra positiva (santificación de María en el primer instante de su ser natural).

Aduce primeramente razones y testimonios de la Sagrada Escritura y de la Tradición, contrarios al privilegio inmaculado de María, para afirmar después la tesis inmaculista. Es el método clásico entre los escolásticos: "Videtur quod sic... CONTRA...".

Así está planteada la cuestión por Tomás de Strasbourg:

"Utrum Virgo gloriosa, quae a Deo fuit praeelectia, ut filium Dei conciperet, fuerit concepta in originali peccato. Et videtur quod sic. Quia a lege communi omnium hominum naturali propiagatione conceptorum non excipitur Virgo Maria: sed concipi in originali peccato est de lege communi omnium hominum, iuxta illud Augustini De fide ad Petrum: "Firmissime tene, et nullatenus dubites, omnem hominem, qui per concubitum viri, et mulieris concipitur, cum peccato originali nasci, impietati subditum, mortique subiectum, et ob hoc natura irae nasei filium, de qua dicit Apostolus: "Eramus enim et nos natura filii irae, sicut et ceteri", a qua ira nullus liberatur nisi per fidem mediatoris Dei et hominum, Iesu Christi, qui sine peccato concepitus est, sine peccato natus, sine peccato mortus.

ConTra. Illud quod decuit filium Dei respectu eius, quam in matrem 
elegit, pie credundum est, quod hoc opere adimpleverit; sed Dei filium decuit glorisam suam matrem ab omni macula praeservare: ergo, etc." 73 .

$Y$ entramos ya de lleno en la exposición de las pruebas que vinculan para María la inmunidad de la culpa original, que abarcan todo el primer artículo de la distinción III.

Aunque en lo que se refiere a los argumentos y al método de exposición sigue, en general, la línea marcada por sus antecesores y contemporáneos, principalmente por Guillermo de Ware (en los argumentos de razón), Erveo Natal y Durando de Saint-Pourcain (en las pruebas contra la doctrina de Enrique de Gante), delinea perfectamente el estado de la cuestión y, recurriendo también al argumento litúrgico de la fiesta de la Inmaculada, sabe armonizar con verdadero acierto y maestría la universalidad del pecado y de la redención con la singularidad de la concepción de María, preservada de él por intervención divina.

73 In 3 Sent., d. 3, q. 1. En cuanto al texto de Tradición tomado del tratado De fide ad Petrum, c. 26, n. 69: PL. 40, 774, notemos que Tomás de Strasbourg atribuye erróneamente a San Agustín una obra que en realidad pertenece a San Fulgencio de Ruspa. Cfr'. PL. 40, 751-752.

Las citas de la Sagrada Escritura, contenidas en el texto anterior, están tomadas de la Epístola a los Efeisios, 2, 3 (= eramus enim et nos-natura filii irae sicut et ceteri) y de la Epístola I a Timoteo, 2, 5 (= unusis enim Deus, unus et mediator Dei et hominum, homo Christus Iesusi), tomadia "ad sensum". 